\title{
Effective skill: a new theoretical perspective on the relation between skills, skill use, mismatches, and wages
}

Citation for published version (APA):

van der Velden, R., \& Bijlsma, I. (2019). Effective skill: a new theoretical perspective on the relation between skills, skill use, mismatches, and wages. Oxford Economic Papers-New Series, 71(1), $145-165$. https://doi.org/10.1093/oep/gpy028

Document status and date:

Published: 01/01/2019

DOI:

10.1093/oep/gpy028

Document Version:

Publisher's PDF, also known as Version of record

Document license:

Taverne

Please check the document version of this publication:

- A submitted manuscript is the version of the article upon submission and before peer-review. There can be important differences between the submitted version and the official published version of record.

People interested in the research are advised to contact the author for the final version of the publication, or visit the DOI to the publisher's website.

- The final author version and the galley proof are versions of the publication after peer review.

- The final published version features the final layout of the paper including the volume, issue and page numbers.

Link to publication

\footnotetext{
General rights rights.

- You may freely distribute the URL identifying the publication in the public portal. please follow below link for the End User Agreement:

www.umlib.nl/taverne-license

Take down policy

If you believe that this document breaches copyright please contact us at:

repository@maastrichtuniversity.nl

providing details and we will investigate your claim.
}

Copyright and moral rights for the publications made accessible in the public portal are retained by the authors and/or other copyright owners and it is a condition of accessing publications that users recognise and abide by the legal requirements associated with these

- Users may download and print one copy of any publication from the public portal for the purpose of private study or research.

- You may not further distribute the material or use it for any profit-making activity or commercial gain

If the publication is distributed under the terms of Article $25 \mathrm{fa}$ of the Dutch Copyright Act, indicated by the "Taverne" license above, 


\title{
Effective skill: a new theoretical perspective on the relation between skills, skill use, mismatches, and wages
}

\section{By Rolf van der Velden ${ }^{a}$ and Ineke Bijlsma ${ }^{b}$}

${ }^{a}$ Research Centre for Education and the Labour Market, Maastricht University, Tongersestraat 53, 6211 LM Maastricht, The Netherlands; e-mail: R.vanderVelden@Maastrichtuniversity.nl

${ }^{\mathrm{b}}$ Research Centre for Education and the Labour Market, Maastricht University

\begin{abstract}
Skills and skill mismatches affect workers' productivity. However, current approaches to measuring this problem fail to specify the underlying mechanism. In this paper, we develop a new perspective by integrating skill proficiency and skill use into a new concept called 'effective skill'. Effective skill is defined as a multiplicative function of skill proficiency and skill use. The intuitive understanding of this concept is that a skill can have no effect on productivity if it is not used and, vice versa, the effect of using skills is moderated by the skill proficiency level. We develop a skill matching model using data from the OECD PIAAC Survey. We show that there is no effect of numeracy on wages, other than through the use of numeracy skills. Moreover, we show that a skill mismatch model based on this concept is superior to alternative skill mismatch models in explaining wage differences.
\end{abstract}

JEL classifications: I26, J24.

\section{Introduction}

Starting with the seminal work of Becker (1964), researchers have looked at the relation between schooling and productivity, typically using Mincerian wage regressions to assess the effect of schooling and experience on wages (Mincer, 1974). In these equations, schooling and experience are used as proxies for skills and wages as a proxy for productivity. These models are primarily supply driven and assume that individual productivity is a function of individual skills. With the large increase in higher education enrolment and the subsequent debate on overeducation, this human capital interpretation of the relation between schooling and productivity has been seriously challenged (Thurow, 1975; Freeman, 1976), leading to stronger emphasis on job characteristics determining productivity and focusing on the potential negative effects of overeducation (Bills, 2003; Cedefop, 2010). Several models and methods have been developed and tested (Van der Velden and van Smoorenburg, 1997; Battu et al., 2000; Hartog, 2000; Verhaest and Omey, 2006), and the general conclusion 
from the empirical evidence is that the effects of schooling and educational mismatches are best explained by matching models that assume that the combination of supply and demand determines productivity (Sattinger, 1993; Groot and Maassen van den Brink, 2000; Hartog, 2000; McGuinness, 2006; Sattinger, 2012; McGuinness and Pouliakas, 2017). That is, productivity is highest when workers' educational level is a good match to the level required for their job. When workers' educational level is higher than the level required for the job, these workers still have a productivity benefit but not fully, since the utilization of their additional schooling in their work is restricted by job characteristics. Conversely, workers who lack some of the schooling required in their job will not reach the same productivity level as their co-workers with a matching educational level.

Although the empirical results of the effects of schooling and mismatches are quite consistent over time and across countries, to simply interpret these as the effect of skills and skill mismatches has proven difficult (Halaby, 1994; Allen and van der Velden, 2001; Green and McIntosh, 2007; Quintini, 2011). Until recently this was partly due to a lack of data that captures adequate measures of education and skill mismatches. The newly developed Programme for the International Assessment of Adult Competencies (PIAAC) from the Organization for Economic Cooperation and Development (OECD) has filled this gap by providing a good opportunity to look at schooling and skills at the same time (OECD, 2013a; Levels et al., 2014).

Still, there are two major issues. One is that the standard wage model does not directly specify how skills can affect productivity. In fact, the process through which skills affect productivity is treated as a black box. The second problem is that having information on skills possessed is not enough. To measure the effects of skill mismatches, we also need information on the skill requirements. The problem is that no large dataset exists that contains direct information on these skill requirements. Instead, several approaches have been developed to proxy for skill requirements, each with their own weaknesses, both theoretically and empirically.

In this paper, we develop a new perspective on the relation between skills and wages by introducing a new concept called 'effective skill'. Effective skill is defined as a multiplicative function of skill proficiency and skill use. The intuitive understanding of this concept is that a skill can have no effect on productivity if it is not used and, vice versa, the effect of using skills is moderated by the skill proficiency level. The new concept is firmly rooted in use-itor-lose-it, engagement, and self-efficacy theories and has a parallel in expectancy theory that relates ability and motivation to performance. The theoretical breakthrough is that the concept of effective skill explicitly specifies the mechanism through which skills affect wages: skills can only affect wages if they are put to productive use. In the paper, we use data from the PIAAC survey to show that this is indeed the case, focusing on the domain of numeracy skills: there is no effect of numeracy on wages, other than through the use of numeracy skills.

We apply this concept to develop the 'effective skill matching model', again focusing on the domain of numeracy skills. The model explains $29 \%$ of the variance in wages, which is much higher than the $23 \%$ found in alternative skill matching models. Moreover, it is not much lower than a standard educational matching model explaining $31 \%$ of the variance in wages. As education imparts more skills than just numeracy, this is in fact an indication that the developed 'effective skill matching model' is very good.

The remainder of the paper is organised as follows. In Section 2, we elaborate the approaches taken to measure skill mismatch. In Section 3, we develop the new concept of 
effective skill that explicitly identifies the mechanism linking skills to productivity. Section 4 describes the data and method, and Section 5 presents the results. In Section 6, we discuss an important issue relating to the measurement of mismatch and present an innovative way to address this. Section 7 concludes.

\section{Earlier approaches to measuring skill mismatch}

As indicated above, no direct information exists on the skill requirements in a job. Instead, three approaches have been developed to provide an indirect proxy of these skill requirements: workers' self-assessment (WS), job requirement approach (JRA), and realised matches (RM). The WS approach typically asks the worker directly about the importance of certain skills in the job (e.g. 'On a scale from 0 to 10, how important are the following skills for doing your current job?'; see Cedefop, 2015). This approach has been criticised for lack of an objective anchor (Allen and van der Velden, 2005) and social bias ('talking up one's job') and is usually regarded as inferior to other approaches (Verhaest and Omey, 2006).

The JRA or task approach (e.g. Green et al., 2013; Desjardins, 2014; Pouliakas and Russo, 2015; Handel, 2017; Russo, 2017) takes a different perspective than the WS: instead of asking about the importance of a certain skill in a job, this approach asks about its time intensity or frequency of use. A typical question would be 'In your job, how often do you usually read letters, memos, or e-mails?' (OECD, 2013b). The interpretation is that this reflects the skill requirements on the job (hence the term 'job requirements approach'). The construct is then used to compare the level of skill proficiency to the level of skill use to determine whether a work is well matched, or in a situation of mismatch (e.g. Allen et al., 2013; Desjardins, 2014). A fundamental problem with the JRA is that the use of skills is not necessarily a good proxy for skill requirements. The two concepts used to construct the mismatch variable, skill use and skill proficiency, are, in practice, closely linked, both empirically and theoretically. This makes it difficult to regard skill use as an independent measure of skill requirement, since it also reflects skill proficiency. We will return to that in Section 3.

The RM approach takes the average or median skill level in an occupation as the required skill level and defines a worker as overskilled or underskilled if the worker has a skill proficiency level of-usually-one standard deviation above or below that occupation-specific level (e.g. Perry et al., 2014). One problem with the RM approach is that the definition of 'well matched' is always relative (Battu et al., 2000; Hartog, 2000; Verhaest and Omey, 2006). Basically, the approach defines workers with an average skill proficiency level in a certain occupation as well matched regardless of the actual required skill level. Another problem is that the RM approach uses occupational categories to assess the average level. However, these occupational categories are heterogeneous and contain occupations that could differ in required skill levels. This means that workers may be wrongfully classified as matched or mismatched.

\section{Towards a new theoretical model}

A critical assumption of the JRA is that the use of skills is a proxy for skill requirements. If this is true, the two concepts of skill use and skill proficiency can be used to construct a mismatch variable. However, our view is different. We think that skill use is not a proxy for 
skill requirements and that it is hard to disentangle the skill use from skill proficiency. There are at least three strands of literature that support this view: use-it-or-lose-it, selfefficacy, and engagement theories.

The use-it-or-lose-it-theory (Mincer and Ofek, 1982; Bynner and Parsons, 1998; Krahn and Lowe, 1998; Salthouse, 2006; Desjardins and Warnke, 2012) argues that skills that are not being used depreciate over the life cycle. Levels and van der Velden (2018) used PIAAC data to document the factors that affect the acquisition and decline of skills over the life cycle. They concluded that the use of skills is strongly related to hampering or accelerating skill proficiency, although the causal direction is not quite clear. People may lose skills because they do not use them anymore, or they may have stopped using them because they have lost them.

Self-efficacy and engagement theories also suggest that the two concepts are closely interlinked. Self-efficacy theory, developed by Bandura (1977), states that task-related selfefficacy increases the likelihood of being engaged in a more challenging task, thus increasing the skill level and self-efficacy. Self-efficacy is one of the motivational variables that were studied as one of the driving factors of engagement, which is a result of cognitive factors, motivational factors, as well as a positive attitude to use certain skills (Guthrie and Wigfield, 2000). Reading engagement and numeracy engagement are considered driving factors in the acquisition of these key skills (OECD, 2012).

If the concepts of skill use and skill proficiency are so closely linked, we need to rethink their relation to productivity. Are skill use and skill proficiency two sides of the same coin or are they different? One of the driving questions challenging the human capital interpretation of the relation between schooling and wages is: Why would employers pay for schooling that is not required? We can pose a similar question for skill proficiency: Why would employers pay for skills that are not used? All of the previous empirical work on the relation between skills and wages implicitly assumes that the wage premium for skills is related to using those skills on the job. If that is not the case, we would be back to a pure signalling or credential type of explanation (Spence, 1973; Collins, 1979), where employers are assumed to pay for schooling or skills that are not actually required on the job. Most of the empirical evidence, however, suggests that this is not the case (Hanushek and Woessmann, 2011; Hanushek et al., 2015).

We believe that we need to develop a concept that firmly integrates skill proficiency and skill use into one new concept: 'effective skill'. More specifically, we assume that productivity is a multiplicative function of two inputs: skill proficiency and skill use. The intuitive understanding of this assumption is straightforward. Skills can affect productivity, but only when they are put to use. Although one can think of cases where this relation is less straightforward, ${ }^{1}$ we would argue that this holds for all skills whose use is assumed to be central for functioning in a job. This is true for all key skills, such as numeracy, literacy, problem solving, and social skills. There is no reward for skills that are not being used. This is in line with a basic human capital framework, assuming that there can only be a reward for skills that are actually used. Conversely, the effect of using a particular skill is moderated by the skill proficiency level. If the proficiency level is low, using that skill has less effect on productivity than when the proficiency level is high.

1 For example, a pilot needs to be very proficient in dealing with emergency situations and will also be rewarded for that type of skill, although it is unlikely that this skill will be used often. 
The theoretical innovation of this concept is that it addresses one of the problems in the current wage models that fail to specify why skills would affect productivity. By explicitly acknowledging that key skills can only affect wages when they are being used, we specify the underlying mechanism linking skills to productivity. This idea linking productivity to a multiplicative function of two inputs is not new. In the early 1960s, the psychologist V.H. Vroom (1964) developed expectancy theory in his study on the motivations for decision making. According to his theory, performance is a multiplicative function of ability and motivation. This theory has been applied and tested in different settings, mainly in education and in work. A review by van Iddekinge et al. (2014) shows that the empirical research has provided mixed evidence, except in the case of job performance, where the results seem to support this theory.

We now express this as a formal model. Let us define: $\mathrm{P}_{\mathrm{i}}=$ productivity level of individual $\mathrm{i} ; \mathrm{W}_{\mathrm{i}}=\log$ hourly wage of individual $\mathrm{i}$; $\mathrm{S}_{\mathrm{i}}=$ skill proficiency of individual $\mathrm{i}$;

$\mathrm{U}_{\mathrm{i}}=$ skill use of individual $\mathrm{i} ; \mathrm{ES}_{\mathrm{i}}=$ effective skill of individual $\mathrm{i} ; v_{\mathrm{i}}=$ idiosyncratic error term. Then,

$$
\mathrm{P}_{\mathrm{i}}=\mathrm{W}_{\mathrm{i}}=\alpha+\beta \mathrm{S}_{\mathrm{i}} * \mathrm{U}_{\mathrm{i}}+v_{\mathrm{i}}=\alpha+\beta \mathrm{ES}_{\mathrm{i}}+v_{\mathrm{i}}
$$

To assess the effect of skill mismatches, we need to turn this equation into a standard matching model. We follow the conventional so-called overeducation-required educationundereducation model (ORU) developed by Duncan and Hoffman (1981). In this model, own schooling level (OS) is broken down into its three components:

- Years of required education (RE)

- Years of overeducation (OE), defined as OS - RE if OS $>$ RE and zero otherwise

- Years of undereducation (UE) defined as RE - OS if OS $<$ RE and zero otherwise

This means that $\mathrm{OS}=\mathrm{RE}+\mathrm{OE}-\mathrm{UE}$ and the standard wage regression is

$$
\mathrm{W}_{\mathrm{i}}=\alpha+\beta 1 * \mathrm{RE}_{\mathrm{i}}+\beta 2 * \mathrm{OE}_{\mathrm{i}}+\beta 3 * \mathrm{UE}_{\mathrm{i}}+v_{1}
$$

In other words, the ORU model assumes a wage premium for required years of schooling $(\beta 1)$, a wage premium for years of overeducation $(\beta 2)$, and a wage penalty for years of undereducation ( $\beta 3)$. Empirical findings around the world usually show that $\beta 1>\beta 2>$ (absolute value of) $\beta 3$ (Groot and Maassen van den Brink, 2000; Hartog, 2000; Levels et al., 2014).

We can develop a similar model for skill mismatches. We assume that each occupation has a typically required level of effective skill. Workers can perform above or below these standards and will receive a wage premium/penalty accordingly. However, in line with the matching theories and the empirical results from educational mismatch research, there are decreasing returns/penalties to performing above or below the standard.

Let us assume that both $S_{i}$ and $U_{i}$ are standardised variables with a mean of 10 and a standard deviation of one. ${ }^{2}$ Now let

$\mathrm{RES}_{\mathrm{i}}=$ mean $\mathrm{ES}_{\mathrm{ij}}=$ typically required effective skill of individual $\mathrm{i}$ in occupation $\mathrm{j}$

$\mathrm{OES}_{\mathrm{i}}=\left(\mathrm{ES}_{\mathrm{i}}-\mathrm{RES}_{\mathrm{i}}\right)$ for $\left(\mathrm{ES}_{\mathrm{i}}-\mathrm{RES}_{\mathrm{i}}\right)>0.5$, else $0=$ extent to which individual $\mathrm{i}$ has a higher effective skill level (at least 0.5 standard deviations higher) than typically required in occupation j

2 A mean of 10 is used to avoid negative and zero values. The results are not sensitive to which positive value is used, as long as it is large enough that negative or zero values are avoided. 
$\mathrm{UES}_{\mathrm{i}}=\left(\mathrm{RES}_{\mathrm{i}}-\mathrm{ES}_{\mathrm{i}}\right)$ for $\left(\mathrm{RES}_{\mathrm{i}}-\mathrm{ES}_{\mathrm{i}}\right)>0.5$, else $0=$ extent to which individual $\mathrm{i}$ has a lower effective skill level (at least 0.5 standard deviations lower) than typically required in occupation j

Now eq. (1) can be written as

$$
\mathrm{W}_{\mathrm{i}}=\alpha+\beta 1 * \mathrm{RES}_{\mathrm{i}}+\beta 2 * \mathrm{OES}_{\mathrm{i}}+\beta 3 * \mathrm{UES}_{\mathrm{i}}+v_{1}
$$

As in previous research, we expect the returns to required effective skill to be higher than the returns to overperformance in effective skill and these, in turn, to be higher (in absolute terms) than the returns to underperformance in effective skill. Note that we use an RM approach to identify workers as matched or non-matched. Note also that overperformance or underperformance in effective skill can arise from either or both of the underlying components (skill proficiency or skill use) and that workers may compensate for a lower proficiency level with a higher skill use to obtain the same productivity level.

\section{Data and method}

We use the PIAAC dataset (OECD, 2013b) that assesses the proficiency of the adult population in key information-processing skills. The survey is designed to be crossculturally and cross-nationally valid. The original dataset comprised 24 countries and approximately 166,000 respondents. The national samples are representative samples of noninstitutionalised persons aged 16 to 65 years. Most countries have around 5,000 respondents in the sample, with the exception of Canada, which has more than 27,000 respondents. From this dataset, we excluded Australia, because of data protection rules, and the Russian Federation, because of data quality concerns. From the Canadian sample, we took a random sample of about $20 \%$ to avoid overrepresentation of the Canadian sample in the total dataset.

The PIAAC survey assesses the proficiency of respondents in three key informationprocessing skills: numeracy, literacy, and problem solving in technology-rich environments. We only focus on numeracy and check the comparability of the results for literacy. Adaptive testing and item response techniques were used to calculate 10 plausible values (PVs) for each of these two domains. Together, these PVs for numeracy and literacy provide an unbiased estimate of the 'real' score if the respondent would have taken all the numeracy- and literacy-related items (OECD, 2013b). The numeracy scale has a range from zero to 500 , with an OECD international average of 273 , and the literacy scale has a similar range, with an OECD average of 270 .

Furthermore, we constructed two scales based on items that reflect the use of numeracy and literacy skills at work: six items on the use of numeracy skills at work (e.g. 'In your job, how often do you usually calculate prices, costs, or budgets?') and eight items on the use of reading skills ${ }^{3}$ at work (e.g. 'In your job, how often do you usually read letters, memos, or e-mails?'). We computed simple average scores for these sets of items. The Cronbach alphas for these two scales are 0.803 and 0.806 , respectively.

To estimate the average skill proficiency and skill use levels for each two-digit ISCO occupation category in each of the countries, we use the robust estimates developed by

3 The PIAAC questionnaire also has four items related to writing skills (e.g. 'In your job, how often do you usually write letters, memos, or e-mails?'). However, these were not used, as the reading items are conceptually closer to the test domain of literacy than the writing items. 
Allen and Bijlsma (2015; for details, see online appendix C in the Supplementary material). For the individual effective skill measure and skill mismatch, we use eqs (1) and (3). ${ }^{4}$

Next we selected male full-time working employees. This selection was made to avoid different wage-setting regimes for part-timers and women. In addition, the relation between skills and earnings for the self-employed is quite different from that for employees. Fulltime is defined as working 32 hours or more per week. We only selected respondents for whom we had valid information on skill proficiency, skill use, and hourly wages. Wages were trimmed per country, omitting the 1st and 99 th percentiles of the respondents in each country.

The resulting dataset includes 22 countries and 32,420 individuals. To avoid outliers in the distribution of skill proficiency per country-specific two-digit ISCO occupation category, we remove the 1st and 99th percentiles of the respondents in each occupation category per country. This leaves us with a working sample of 29,550 individuals. We use a multilevel model to account for the nested structure, allowing for error clustering at the country level. We estimate the following model:

$$
\mathrm{W}_{\mathrm{ic}}=\alpha_{\mathrm{c}}+\beta 1 \mathrm{~S}_{\mathrm{ic}} * \mathrm{U}_{\mathrm{ic}}+\beta 2 \mathrm{C}_{\mathrm{ic}}+v_{\mathrm{ic}}+\omega_{\mathrm{c}}=\alpha_{\mathrm{c}}+\beta 1 \mathrm{ES}_{\mathrm{ic}}+\beta 2 \mathrm{C}_{\mathrm{ic}}+v_{\mathrm{ic}}+\omega_{\mathrm{c}}
$$

where, for individual $\mathrm{i}$ in country $\mathrm{c}, \mathrm{W}_{\mathrm{ic}}$ is the natural logarithm of the (PPP converted) hourly wages, $\alpha_{c}$ is a country-specific constant, $S_{i c}$ is the skill proficiency level, $\mathrm{U}_{\mathrm{ic}}$ is the corresponding skill use, $E S_{i c}$ is the effective skill measure of eq. (1), $C_{i c}$ is a vector of control variables (with only the two variables age and age squared), ${ }^{5}$ and $v_{\mathrm{ic}}$ and $\omega_{\mathrm{c}}$ are idiosyncratic error terms at the individual and country levels, respectively.

We compare the 'effective skill model' with alternative specifications to check the validity of our assumption that productivity is a multiplicative function of skill proficiency and skill use. We compare eq. (4) with a model in which we include the skill proficiency level and skill use level as separate effects, as well as a model in which we include both main effects and the interaction effect:

$$
\begin{aligned}
& \mathrm{W}_{\mathrm{ic}}=\alpha_{\mathrm{c}}+\beta 1 \mathrm{~S}_{\mathrm{ic}}+\beta 2 \mathrm{U}_{\mathrm{ic}}+\beta 3 \mathrm{C}_{\mathrm{ic}}+v_{\mathrm{ic}}+\omega_{\mathrm{c}} \\
& \mathrm{W}_{\mathrm{ic}}=\alpha_{\mathrm{c}}+\beta 1 \mathrm{~S}_{\mathrm{ic}}+\beta 2 \mathrm{U}_{\mathrm{ic}}+\beta 3 \mathrm{~S}_{\mathrm{ic}} * \mathrm{U}_{\mathrm{ic}}+\beta 4 \mathrm{C}_{\mathrm{ic}}+v_{\mathrm{ic}}+\omega_{\mathrm{c}}
\end{aligned}
$$

If only the main effects in eq. (6) are significant, then the assumption that productivity is a multiplicative function of skill and effort must be rejected. If only the interaction term is significant, then our assumption is fully supported.

From eq. (5), we also derive information on whether or not both components $S_{\text {ic }}$ and $U_{\text {ic }}$ should have equal weights when calculating the effective skill measure. Remember that we started by standardizing both variables with a mean of 10 and a standard deviation of one,

4 For the proficiency scores, we use the average of the PVs for each domain. This was done for computational reasons. For the point estimates, this should not be a problem, but using the average of the $10 \mathrm{PVs}$ can lead to underestimation of the standard errors. As a robustness check, we checked the results for several separate PVs to see whether they produce the same results. This is indeed the case (see online appendix Table A2).

5 Online appendix A presents a number of robustness checks to see whether results change if we focus on literacy instead of numeracy (Table A1), include other control variables, i.e. level of education or occupational dummies (Table A5), or conduct separate analyses per education level (Table A6) or one-digit ISCO occupation (Table A7). These do not substantially change our main conclusions. 
thus giving both components the same weight in the product term. However, if eq. (5) shows that parameters $\beta 1$ and $\beta 2$ are different, we can adjust these weights to properly reflect the contribution of each component in the effective skill measure.

We next estimate the 'effective skill matching model', using the three variables from eq. (3):

$$
\mathrm{W}_{\mathrm{ic}}=\alpha_{\mathrm{c}}+\beta 1 \mathrm{ESM}_{\mathrm{ic}}+\beta 2 \mathrm{C}_{\mathrm{ic}}+v_{\mathrm{ic}}+\omega_{\mathrm{c}}
$$

where $\mathrm{ESM}_{\mathrm{ic}}$ is a vector of the three effective skill matching variables $\mathrm{RES}_{\mathrm{ic}}, \mathrm{OES}_{\mathrm{ic}}$, and $\mathrm{UES}_{\text {ic }}$ from eq. (3).

In the next model, we test whether the effects of the effective numeracy matching model are affected by effective matching variables in literacy. First, we test eq. (7) separately for the literacy domain and then add both domains in the model:

$$
\mathrm{W}_{\mathrm{ic}}=\alpha_{\mathrm{c}}+\beta 1 \mathrm{ESM}_{\mathrm{Lic}}+\beta 2 \mathrm{ESM}_{\mathrm{Nic}}+\beta 3 \mathrm{C}_{\mathrm{ic}}+v_{\mathrm{ic}}+\omega_{\mathrm{c}}
$$

where the subscripts $\mathrm{N}$ and $\mathrm{L}$ denote the numeracy and literacy domains, respectively. By comparing the results for literacy and numeracy from eq. (7) with those from eq. (8), we can see whether the parameter estimates are affected by including other skill domains. If the parameters of both models are substantially different, this implies that the parameters found in eq. (7) may be over- or underestimated.

Finally, we compare the new model with alternative models, as suggested by Allen et al. (2013), Pellizari and Fichen $(2013,2017)$, and a standard ORU model. The following alternative models are estimated:

$$
\mathrm{W}_{\mathrm{ic}}=\alpha_{\mathrm{c}}+\beta 1 \mathrm{~S}_{\mathrm{ic}}+\beta 2 \mathrm{U}_{\mathrm{ic}}+\beta 3 \mathrm{OU}_{\mathrm{ic}}+\beta 4 \mathrm{UU}_{\mathrm{ic}}+\beta 5 \mathrm{C}_{\mathrm{ic}}+v_{\mathrm{ic}}+\omega_{\mathrm{c}}
$$

where $\mathrm{OU}_{\mathrm{ic}}$ and $\mathrm{UU}_{\mathrm{ic}}$ are dummies denoting the overuse (OU) or underuse (UU) of skills according to Allen et al. (2013). ${ }^{6}$

Similarly, we estimate:

$$
\mathrm{W}_{\mathrm{ic}}=\alpha_{\mathrm{c}}+\beta 1 \mathrm{~S}_{\mathrm{ic}}+\beta 2 \mathrm{U}_{\mathrm{ic}}+\beta 3 \mathrm{OS}_{\mathrm{ic}}+\beta 4 \mathrm{US}_{\mathrm{ic}}+\beta 5 \mathrm{C}_{\mathrm{ic}}+v_{\mathrm{ic}}+\omega_{\mathrm{c}}
$$

where $\mathrm{OS}_{\mathrm{ic}}$ and $\mathrm{US}_{\mathrm{ic}}$ are dummies denoting being overskilled (OS) or underskilled (US) according to Pellizari and Fichen $(2013,2017){ }^{7}$

6 Allen et al. (2013) construct a measure of skill mismatch that they call relative use of skill. Using PIAAC data, they standardised both measures of skill use and proficiency for a domain and then subtracted them. Workers with a skill use level of one and a half standard deviations higher than what would have been predicted on the basis of their skill proficiency were classified as overusing their skills, and workers with a level of skill use of one and a half standard deviations lower than what would have been predicted on the basis of their skill proficiency level were classified as underusing their skills.

7 Pellizari and Fichen (2013) first selected all workers who identified themselves as being well matched. They used this group to identify the range of skill proficiency levels per country per onedigit ISCO occupation category for well-matched workers. This range was then trimmed (omitting the lower and upper $5 \%$ ) and regarded as the 'normal' skill range in that one-digit occupation category. Any worker-regardless of whether they regarded themselves as well matched or not-is considered well matched if their skill proficiency levels fell in the country-occupation specific skill ranges. The update by Pellizari and Fichen (2017) follows a similar procedure, but uses two-digit ISCO occupations instead of one-digit. We check whether this makes a difference. 
Table 1. Comparing different specifications of the 'effective skill model' for numeracy

\begin{tabular}{|c|c|c|c|c|c|}
\hline Variables & $\begin{array}{l}\text { Model } 1 \\
(\text { Eq. }(5))\end{array}$ & $\begin{array}{l}\text { Model } 2 \\
(\text { Eq. }(6))\end{array}$ & $\begin{array}{l}\text { Model } 3 \\
(\text { Eq. (4)) }\end{array}$ & \multicolumn{2}{|c|}{$\begin{array}{l}\text { Model } 4 \text { (Eq. (4) } \\
\text { with adj. weights) }\end{array}$} \\
\hline Numeracy proficiency & $\begin{array}{l}13.168 * * * \\
(0.267)\end{array}$ & $\begin{array}{c}1.622 \\
(2.412)\end{array}$ & & & \\
\hline Numeracy use & $\begin{array}{l}9.285 * * * \\
(0.248)\end{array}$ & $\begin{array}{l}-2.557 \\
(2.471)\end{array}$ & & & \\
\hline Proficiency * Use & & $\begin{array}{l}1.173 * * * \\
(0.244)\end{array}$ & $\begin{array}{l}1.114 * * * \\
(0.014)\end{array}$ & \multicolumn{2}{|c|}{$\begin{array}{l}0.918 * * * \\
(0.011)\end{array}$} \\
\hline $\mathrm{N}_{\text {individuals }}$ & 29,047 & 29,047 & 29,047 & \multicolumn{2}{|c|}{29,551} \\
\hline $\mathrm{N}_{\text {countries }}$ & 22 & 22 & 22 & \multicolumn{2}{|c|}{22} \\
\hline $\mathrm{BIC}$ & 26,575 & 26,562 & 26,635 & \multicolumn{2}{|c|}{27,890} \\
\hline Variance components & Intercept model & Model 1 & Model 2 & Model 3 & Model 4 \\
\hline Between variance & 0.119 & 0.104 & 0.104 & 0.104 & 0.103 \\
\hline Within variance & 0.204 & 0.145 & 0.145 & 0.145 & 0.147 \\
\hline Total variance & 0.323 & 0.249 & 0.249 & 0.249 & 0.250 \\
\hline
\end{tabular}

Parameters multiplied by 100; standard errors in parentheses; $* * p<0.01$; Controls include age, age ${ }^{2}$. Source: PIAAC, authors' calculations.

The alternative ORU model is the standard Duncan-Hoffman (1981) model in which we look at educational mismatches instead of skill mismatches:

$$
\mathrm{W}_{\mathrm{ic}}=\alpha_{\mathrm{c}}+\beta 1 \mathrm{RE}_{\mathrm{ic}}+\beta 2 \mathrm{OE}_{\mathrm{ic}}+\beta 3 \mathrm{UE}_{\mathrm{ic}}+\beta 4 \mathrm{C}_{\mathrm{ic}}+v_{\mathrm{ic}}+\omega_{\mathrm{c}}
$$

where $\mathrm{RE}_{\mathrm{ic}}$ denotes years of required education in occupation $\mathrm{j}$ in country $\mathrm{c},{ }^{8} \mathrm{OE}_{\mathrm{ic}}$ denotes years of overeducation (defined as own schooling $O S_{i}-R_{i c}$ if $O S_{i}>R_{i c}$ and zero otherwise), and $\mathrm{UE}_{\mathrm{ic}}$ denotes years of undereducation (defined as $\mathrm{RE}_{\mathrm{ic}}-\mathrm{OS}_{\mathrm{i}}$ if $\mathrm{OS}_{\mathrm{i}}<\mathrm{RE}_{\mathrm{ic}}$ and zero otherwise). Since education imparts more skills than just numeracy (or literacy), we expect this ORU model to be better than the model in which we include only the 'effective skill matching model' with respect to numeracy.

\section{Results}

First, we compare the 'effective skill model' with alternative specifications to check the validity of the first assumption, namely, that productivity is a multiplicative function of skill proficiency and skill use. We compare eq. (4) with a model in which we include the skill proficiency level and skill use level as separate effects (eq. (5)), as well as a model in which we include both the main effects and the interaction effect (eq. (6)). The results are displayed in Table 1.

When only the main effects are entered in the model (eq. (5)), both numeracy proficiency and the use of numeracy skills show a positive significant effect on wages.

8 We use Allen and Bijlsma's (2015) method to calculate the country-specific estimates of the required years of schooling per two-digit ISCO occupation category. 
A one-standard-deviation increase in numeracy skills raises wages by $13.2 \%$, and a similar increase in the use of numeracy skills raises wages by $9.3 \% .^{9}$ This model (Model 1) explains $12.6 \%$ of the between-country variation $(=(0.119-0.104) / 0.119 * 100)$ and $28.9 \%$ of the within-country variation. However, with the inclusion of the interaction effect in eq. (6) (Model 2), these main effects are no longer significant and only the interaction effect is significant whereas the residual variation stays the same. Including only the interaction term as in eq. (4) (Model 3) hardly changes these parameters. ${ }^{10}$ This is very strong support for our assumption that states that productivity is a multiplicative function of skill proficiency and skill use. Numeracy skills have no effect on wages other than through using these skills and, vice versa, the effect of using numeracy skills is moderated by the numeracy proficiency.

As indicated, the parameters in eq. (5) (Model 1) show that numeracy proficiency affects wages more than using these skills does. The difference in effect size is about 1.5 to one. This result suggests that we need to readjust the weights of these components in the effective skill measure such that they correspond to this difference. This is done by setting the standard deviation of the skill proficiency variable to 1.5 instead of 1.0. The last column of Table 1 presents the results of eq. (4) using these adjusted weights. The results (Model 4) show that an increase of one standard deviation in the skill proficiency component of effective numeracy yields a wage premium of $13.8 \%(=0.918 * 1.5 * 10)$ while a similar increase in the skill use component yields a wage premium of $9.2 \%(=0.918 * 1.0 * 10){ }^{11}$

In Table 2, we present the results for the 'effective skill matching model' as outlined in eq. (7), using the adjusted weights. As expected, we find that required effective numeracy has a strong positive effect on wages. A one-standard-deviation increase in the skill proficiency component of effective numeracy yields a wage premium of $16.9 \%$ $(=1.129 * 1.5 * 10)$ while a similar increase in the skill use component yields a wage premium of $11.3 \%(=1.129 * 1.0 * 10)$. Overperformance in effective numeracy is also positively rewarded, but not as much. Expending one standard deviation more in the skill proficiency component of effective numeracy yields a wage premium of $7.8 \%$ while a similar increase in the skill use component yields a wage premium of $5.2 \%$. As expected, underperformance in effective numeracy is penalised. Expending one standard deviation less in the skill proficiency component of effective numeracy is associated with a wage penalty of $8.8 \%$ while a similar decrease in the skill use component is associated with a wage penalty of $5.8 \%$.

If we compare these results with what is usually found in the educational mismatch literature, we see a strong similarity. The returns to required effective skill levels are greater than the returns to overperformance or underperformance in effective skill. However, contrary to the literature, we do not find that the wage penalty for the underperformance of

9 We checked for multicollinearity. We see no indications for this: the mean VIF of 1.20 is well below the usual threshold of 10 and the $\mathrm{Cl}$ of 1.548 is well below the threshold of 30 .

10 An F-test comparing Model 2 and Model 4 using adjusted weights indicates that the main effects are not jointly significant. This indicates that the interaction term sufficiently captures the effects of the separate terms.

11 Online appendix A shows the results of several robustness checks, such as quantile regression analyses (Figure A1) or the use of different specifications of the underlying variables (Tables $A 3$ and A4). These do not change the results. 
Table 2. 'Effective skill matching model' for numeracy with regards to log hourly wage (eq. (7))

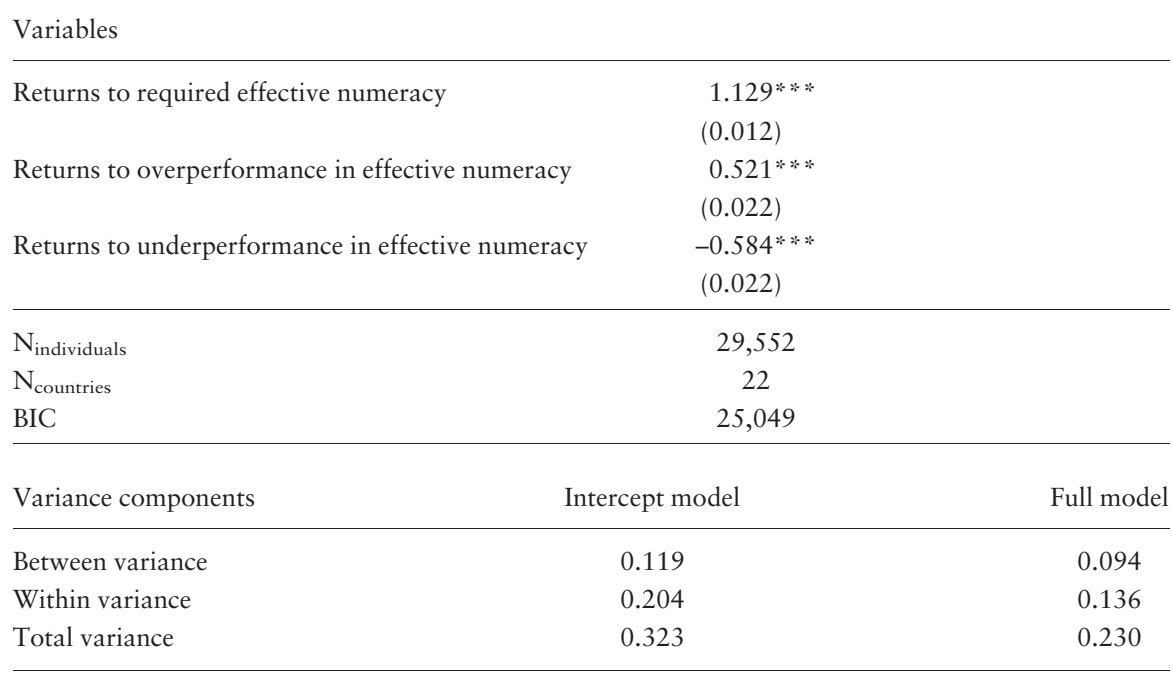

Parameters multiplied by 100; standard errors in parentheses; $* * p<0.01$; Controls include age, age ${ }^{2}$. Source: PIAAC, authors' calculations.

effective skill is less in absolute terms than the wage premium for the overperformance of effective skill. Instead, we find that the effect is more or less the same. This finding could be explained by the fact the results usually found for undereducation are obscured, as the group of undereducated is selective and compensates for undereducation with skills acquired through experience. If we look at the effective skill as presented here, we observe a more linear relation between effective skill and productivity, with an additional premium for workers who perform at a matching effective skill level. ${ }^{12}$

Table 3 compares the 'effective skill matching model' for numeracy with a similar model for literacy, both separately and together. For comparison, column (1) repeats the estimates for the numeracy domain, as presented earlier in Table 2. Column (2) shows the estimates for the literacy domain separately. These follow the same pattern as the numeracy items, but always with slightly higher values, especially the rewards and penalties for overand underperformance. The return to typically required effective literacy is 1.232 , compared to 1.129 for numeracy, corresponding to an approximately $9 \%$ difference. The difference in the returns to overperformance in effective literacy is greater $(0.883$ vs. 0.521$)$, an approximately $70 \%$ difference. The same also holds for underperformance in effective literacy. However, in a joint model (eq. (8), column (3)), the numeracy items clearly outweigh the literacy-related items, thus confirming previous results showing numeracy having a stronger effect on wages compared to literacy (Levels et al., 2014). The magnitudes of the effects are reduced by about $70-80 \%$ for the literacy items and only about $10-25 \%$ for the numeracy items. In the joint model, the effect of required effective literacy is almost half that of required effective numeracy. We conclude that the effects of effective skill in the 
Table 3. 'Effective skill matching model' for literacy and numeracy with regards to log hourly wage

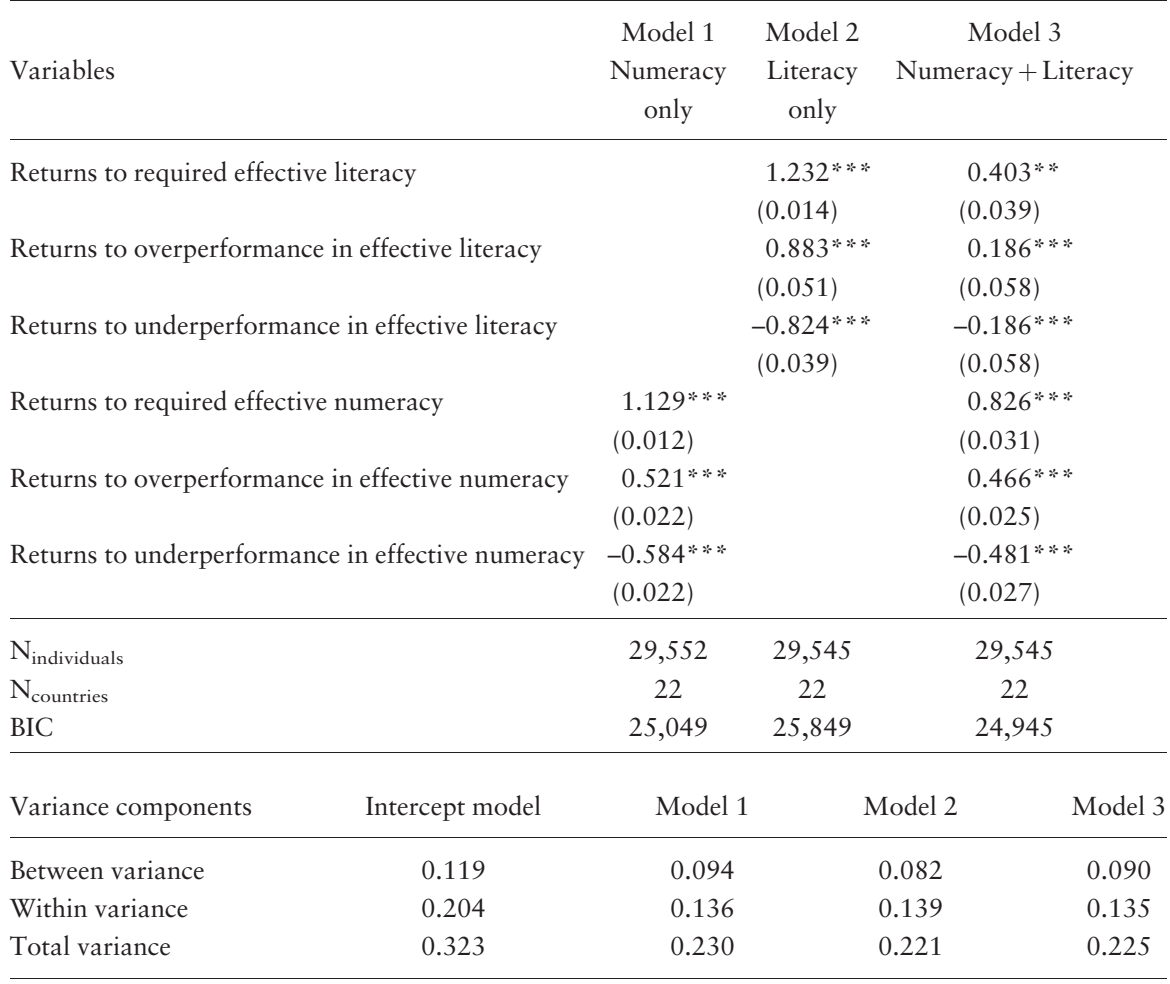

Parameters multiplied by 100 ; standard errors in parentheses; $* * p<0.01, * * p<0.05$; Controls include age, age2.

Source: PIAAC, authors' calculations.

different domains are not simply additive: the effects of numeracy and literacy are bundled (Heckman and Scheinkman, 1987), which leads to an overestimation of the effects of one skill domain if the other is not included as well. This result holds more strongly for the literacy domain than for the numeracy domain. We will take this into account when looking at the results of the following analyses, which focus on numeracy again. ${ }^{13}$

In Table 4, we show the results of our 'effective skill matching model' and compare it with some other models. Column (1) shows the same parameters as in Table 2. Column (2) presents the results of the method of Allen et al. (2013), with the numeracy proficiency level, the numeracy use level, and dummies for the relative overutilization or underutilization of numeracy compared to the numeracy proficiency level. To compare the results,

13 Online appendix B presents several additional analyses incorporating institutional characteristics and their interactions with the 'effective skill matching model'. The 'effective skill matching model' shows the strongest effects in countries with a low percentage of workers falling under a collective wage agreement (Table B2), which is consistent with labour market institution theory (Marsden, 1999). Moreover, they show that there is a wage penalty for working in the public sector but this is highest for workers in occupations with high required effective numeracy (Table B3). 
Table 4. 'Effective skill matching model' for numeracy with regards to log hourly wage compared with alternative models

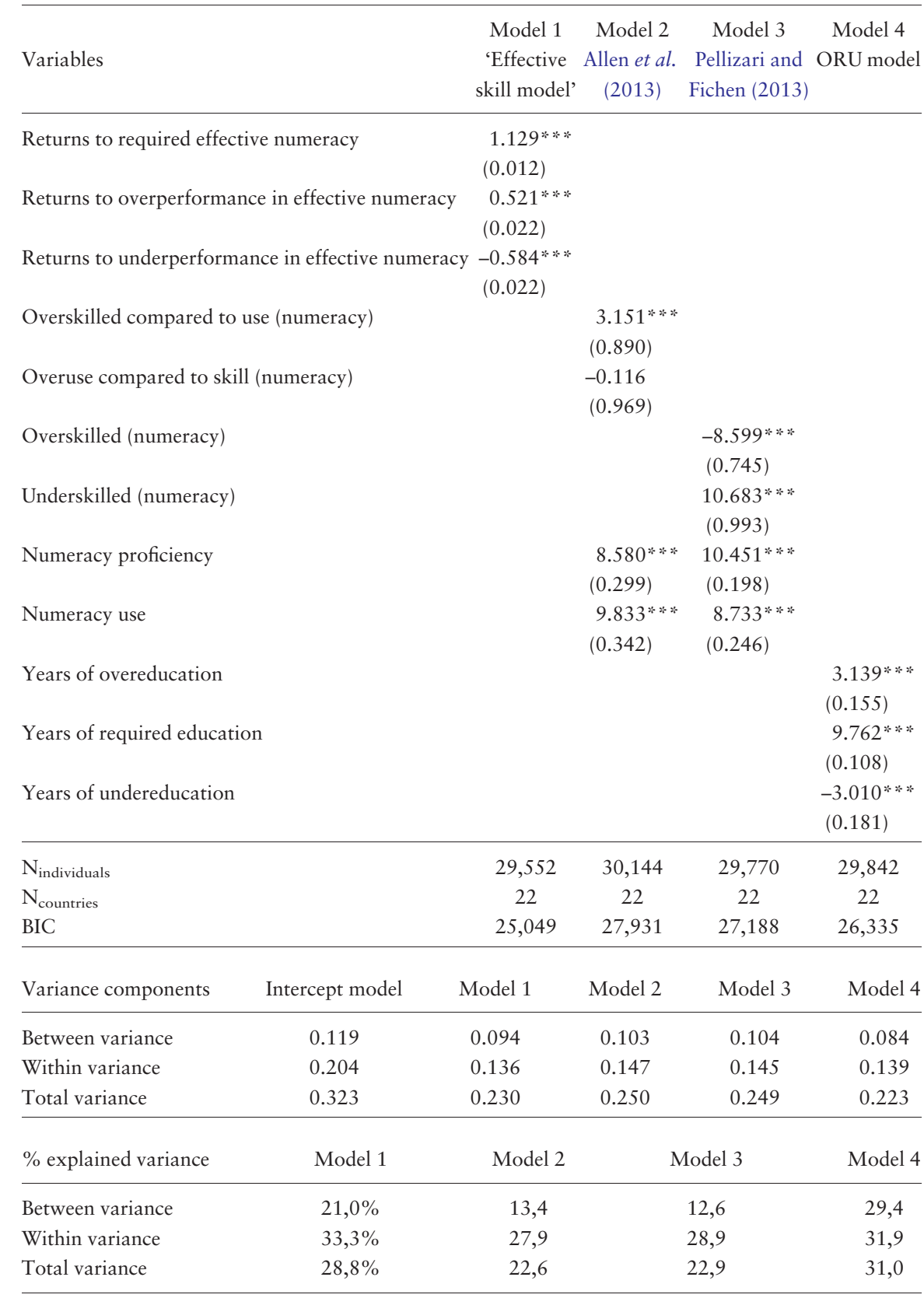

Parameters multiplied by 100; standard errors in parentheses; $* * p<0.01$; Controls include age, age ${ }^{2}$. Source: PIAAC, authors' calculations. 
numeracy proficiency and numeracy use have the same scale as in the previous models (with a mean of 10 and standard deviations of 1.5 and 1.0, respectively). The results show the expected positive effects for numeracy proficiency and numeracy use. One standard deviation of extra skills yields a wage premium of $12.9 \%(=8.58 * 1.5)$ and one standard deviation of more use yields a wage premium of $9.8 \%$. The effect of the relative overuse of numeracy compared to the numeracy proficiency level is not significant; however, being overskilled relative to the use of numeracy (which is the same as the underuse of numeracy skills) has a significant positive effect. Note that the reference here is skill use on the job, which turns the parameter into a positive effect (like the effect of overeducation in the ORU model). Being overskilled in numeracy compared to the use of numeracy skills pays off with a premium of about $3.2 \%$. Nevertheless, the model of Allen et al. (2013) performs less well than the previously introduced 'effective skill matching model'. The percentage of explained variance of the model compared to that of the intercept model is much lower than for the 'effective skill matching model' (22.6\% vs. $28.8 \%$ ). Column (3) shows similar results for the Pellizari and Fichen (2013) model. The return for a one-standard-deviation increase in numeracy proficiency is $15.7 \%$ and a similar increase in the use of numeracy skills incurs a wage return of $8.7 \%$. The penalty for being overskilled is $8.6 \%{ }^{14}$ and the wage premium for being underskilled is $10.7 \%$. Although these effects are all significant, the explained variance of the model is again lower than that of the 'effective skill matching model' $(22.9 \%$ vs. $28.8 \%) .{ }^{15}$ Finally, in column (4), we compare the 'effective skill matching model' with a standard ORU model. To make the results more comparable to those of the 'effective skill matching model', we used the average years of schooling in an occupation as the proxy for required education (using the same algorithm as Allen and Bijlsma, 2015). The results show the familiar outcomes of an approximately $9.8 \%$ increase in wages for each additional year of schooling, a 3.1\% increase in wages for each year of overschooling, and a similar wage penalty for each year of underschooling. Since education imparts more skills than just numeracy, we expected this model to do better than the 'effective skill matching model'. This is indeed the case, but the difference is remarkably small: $31.0 \%$ versus $28.8 \%$. This is again strong support for the 'effective skill matching model', showing that wages are driven by a multiplicative function of skill proficiency and skill use.

\section{Problem of within-occupation heterogeneity}

As shown above, our 'effective skill matching model' is superior to alternative skill mismatch models (Allen et al., 2013; Pellizari and Fichen, 2013, 2017) in terms of explaining wages. Moreover, the concept is theoretically more advanced and well rooted in other theoretical approaches. However, still, we are basically using an RM approach to assess the

14 Note that the reference here is the well-matched worker and not the required skill level, hence the reversal of signs.

15 We also used the Pellizari and Fichen (2017) model, based on two-digit occupations instead of one-digit. This does not affect our conclusion. The overall explained variance is the same $(22.6 \%)$, and the same holds for the effects of skill proficiency and skill use (10.1 and 8.7, respectively). As expected, however, the effects of overskilling and underskilling decrease. This is the same as we find in Table 5 for the Dutch data. Moving from estimates based on one-digit occupations to estimates based on two-digit occupations will lead to a decrease in the effects of over- and underskilling. 
Table 5. 'Effective skill matching model' for numeracy with regards to log hourly wage for one-, two-, and three-digit ISCO levels (results for the Netherlands only)

\begin{tabular}{lccc}
\hline Variables & One-digit ISCO & Two-digit ISCO Three-digit ISCO \\
\hline Returns to required effective numeracy & $1.393 * * *$ & $1.943 * * *$ & $2.237 * * *$ \\
& $(0.054)$ & $(0.076)$ & $(0.102)$ \\
Returns to overperformance in effective numeracy & $0.897 * * *$ & $0.831 * * *$ & $0.777 * * *$ \\
& $(0.119)$ & $(0.149)$ & $(0.121)$ \\
Returns to underperformance in effective numeracy & $-1.249 * * *$ & $-1.292 * * *$ & $-1.283 * * *$ \\
& $(0.149)$ & $(0.163)$ & $(0.130)$ \\
\hline $\mathrm{N}_{\text {individuals }}$ & 1,286 & 1,279 & 1,315 \\
R-square & 0.506 & 0.504 & 0.511 \\
\hline
\end{tabular}

Parameters multiplied by 100; standard errors in parentheses; **p ${ }^{*}<0.01$; Controls include age, age ${ }^{2}$. Source: PIAAC and Dutch LFS, authors' calculations.

effect of skills mismatches, which implies that we are neglecting heterogeneity within occupational categories. Our RM approach uses the mean skill proficiency and skill use level in an occupation as an indicator of the typically required effective skill in that occupation. If occupational groups are very heterogeneous, this could lead to the incorrect assignment of workers as being matched or mismatched. In the previous analyses, we used countryspecific estimates of the required effective skill in each two-digit ISCO occupation category. If we could use a more refined classification, such as a three- or even four-digit ISCO level, this could reduce the problem of within-occupation heterogeneity. Allen and Bijlsma's (2015) method of obtaining robust estimates using a multilevel model already stretches the possibilities of the current PIAAC dataset to the limit and cannot be used to obtain estimates at the three- or four-digit level.

A very promising possibility is to use so-called small area estimation (SAE) models to arrive at more detailed estimates. The basic idea is to use other datasets in combination with the PIAAC data to obtain a more precise and reliable indicator of the required effective skill in detailed occupations. This method has been successfully used by Bijlsma et al. (2017) to estimate literacy proficiency levels at a very detailed regional level (over 200 municipalities in the Netherlands). In this paper, we do the same to arrive at average effective skill levels at the one-, two-, and three-digit ISCO levels. For this, we use the Dutch Labour Force Survey (LFS) data and PIAAC data. The basic idea of SAE is to develop a prediction model on a smaller dataset (PIAAC in this case) and use a larger dataset (LFS in this case) with the same predictors to obtain a synthetic estimate of the dependent variable in each one-, two-, or three-digit ISCO occupation category. The outcome is a weighted sum of direct estimates (from PIAAC) and synthetic estimates where the weight is based on the precision of each of the two estimates (for more details, see online appendix D). We can simulate the effect of aggregation by using SAE models to assess the average effective numeracy level at the one-, two-, and three-digit ISCO levels, respectively. Table 5 provides the results.

The results in Table 5 indicate that the effect of required effective numeracy increases significantly when a more refined classification is used. The effect of required effective numeracy almost doubles in magnitude when moving from the one-digit model to the threedigit model (from 1.393 to 2.237). In addition, using the three-digit ISCO level as a basis 
instead of the two-digit ISCO level (as in the current analysis) significantly increases the effect of required effective numeracy, from 1.943 to 2.237 , an increase of about $15 \%$. Put differently, if one uses broad occupational categories, such as one- or two-digit ISCO occupation categories, one will underestimate the effect of the required effective skill and overestimate the relative effect of performing better or worse than is typically required. Although the effect of required effective numeracy tapers off if we compare the differences between the one- and two-digit model with the differences between the two- and three-digit model, there is no indication that the difference with an even more refined model (i.e. fourdigit model) would be negligible. This means that the effects of required effective skill are likely to be underestimated in all RM models that do not use a very detailed classification, while the effects of individual overperformance or underperformance in effective skill are likely to be relatively overestimated in these models.

\section{Conclusions}

There is convincing evidence that the wage effects of education are largely driven by skills (Hanushek and Woessmann, 2011; Hanushek et al., 2015), although the effects are weaker in less institutionalised settings (Levels et al., 2014) and the mechanism through which skills affect wages is largely left unexplained. There is also strong evidence of different returns in the case of educational mismatches (Groot and Maassen van den Brink, 2000; Hartog, 2000). Generally, workers gain more rewards for years of required education than for years of overeducation, while the penalties for years of undereducation are the least severe.

The research on skill mismatches has produced more mixed results than the research on educational mismatches. This is partly due to the fact that educational and skill mismatches are not the same, due to heterogeneity in skills within educational levels and the sorting of the least-skilled graduates from each level into less complex jobs (Allen and van der Velden, 2001; Green and McIntosh, 2007). However, part of the problem is also the lack of good measures for skill requirements.

In this paper, we have taken a major step forward in our thinking about the relation between skills and productivity, by explicitly linking skill use and skill proficiency into a new concept, effective skill. Effective skill is defined as a multiplicative function of skill proficiency and skill use and has an intuitively appealing notion. A worker's skill proficiency can have no productivity effect if the worker's skills are not being used and, vice versa, the productive use of skills is moderated by the worker's skill proficiency level. The approach is firmly based on engagement literature (OECD, 2012), use-it-or-lose-it theory (Salthouse, 2006), and self-efficacy theory (Bandura, 1977). Moreover, the idea of using a multiplicative function to combine skill proficiency and skill use has its parallel in the performance literature on ability and motivation (Vroom, 1964), where performance is viewed as the result of a multiplicative function of ability and motivation.

Using data from the OECD PIAAC survey, our results showed that the new model developed is indeed much better than the original models of skill proficiency and skill use as separate predictors of wages. In a joint model, the multiplicative term supersedes the effect of all the separate terms, a strong indication of the basic notion of our 'effective skill model', namely, that there can be no productivity effect of skill proficiency when the skills are not being used and vice versa. 
We next developed an 'effective skill matching model' similar to the ORU model (Duncan and Hoffman, 1981) for educational mismatches. The model distinguishes three components, one for the returns to required effective skill, one for the returns to overperformance in effective skill, and one for the penalty to underperformance. The results show that a one-standard-deviation increase in the skill proficiency component of effective numeracy yields a wage premium of $16.9 \%$ while a similar increase in the skill use component yields a wage premium of $11.3 \%$. Overperformance in effective numeracy is also positively rewarded, but not as much: $7.8 \%$ and $5.2 \%$, respectively. As expected, underperformance in effective numeracy is penalised with decreases in wages of $8.8 \%$ and $5.8 \%$.

As indicated earlier, we have to be cautious when interpreting these results. These effects are all estimated without including the effective skill matching variables of other domains. In an additional analysis, we showed that the above-mentioned effects all decrease by about $10-25 \%$ if we include the effective skill matching variables of literacy. This means that the effect sizes mentioned above should be regarded as an upper bound of the effect of required effective numeracy and the over- and underperformance in effective numeracy. On the other hand, the estimates of the required effective numeracy can also be seen as a lower bound, since the results from the SAE models show that using a more refined classification of occupations (e.g. three-digit ISCO level instead of two-digit ISCO level) yields far higher estimates for the required effective numeracy. These estimates are about $15 \%$ higher and, again, could be higher still if one uses an even more refined classification. We return to this issue below but, for the moment, we conclude that the estimates for required effective numeracy will probably not be that different if we include other domains as well as a more refined classification.

The results can best be explained with matching theory. The premium for required effective skill is larger than the premium for expending more effective skill than is typically required on the job, which is in line with typical findings from the educational mismatch literature. When we look at the wage penalties for expending less effective skill than is typically required, we find that this penalty is about as high in absolute terms as the premium for expending more effective skill. In the education mismatch research, the effect of undereducation is usually found to be lower. This result can be explained by the fact that this effect of undereducation is probably underestimated due to selection effects: people who end up in a job for which they are formally undereducated probably have other skills (through experience) that compensate for this lack of required schooling. This is less the case when we look at effective skill, as we do here.

Finally, we compared the 'effective skill matching model' to other models looking at skill mismatches in the labour market, namely, those of Allen et al. (2013) and Pellizari and Fichen $(2013,2017)$ and a simple educational mismatch (ORU) model. The results show that the 'effective skill matching model' is far superior to the two alternative models (Allen et al., 2013; Pellizari and Fichen, 2013) in terms of explained variances (29\% for the 'effective skill matching model' versus $23 \%$ for the other two models) and almost as good as a standard ORU model (31\%). This finding is again strong support for the developed 'effective skill model'. The predictive validity when we look at wage differences is far better than that of any alternative skill matching model. Since schooling imparts more skills than just numeracy, we had expected the ORU model to be better. The fact that the explained variance of our 'effective skill matching model' is very close to that of the ORU model is therefore very encouraging. 
These results do not mean that this approach needs no further development. Although the basic idea of effective skill is empirically and theoretically sound, there is an inherent weak point when we turn this into a matching model. Our 'effective skill matching model' is based on an RM approach, with the two problems associated with that approach. The first problem is that of heterogeneity within occupational groups. Our RM approach uses the average skill proficiency or skill use level in an occupation as an indicator of the required effective skill in that occupation. If occupational groups are very heterogeneous, this could lead to the erroneous assignment of workers as being matched or mismatched. We used SAE models to estimate the effect of the heterogeneity. The results show that using the one-digit ISCO occupation classification as in Pellizari and Fichen (2013) is likely to result in strong underestimation of the effects of required effective skill. Even using the twodigit ISCO classification, as in this paper, results in an underestimation of the effects of required effective skill, as the SAE models based on the three-digit classification show. Because of data limitations in the LFS, we cannot check whether this also holds for using the three-digit ISCO level, but it is likely that a more refined classification, such as the fourdigit ISCO level, will reduce the problem of within-occupation heterogeneity even further.

The second problem with using the RM approach is that of defining a good match. Basically, RM models take the average or median levels as indicating a match but, of course, this need not be the case. There is no simple way to address this problem, since we lack direct information on skill requirements from employers. A good way to solve this would be to obtain expert opinions on the required skill level in each three-digit ISCO occupation category. Basically, this would be equivalent to what has been called the job analyst method of identifying educational mismatches (Hartog, 2000). This job analyst method is generally regarded as potentially the most reliable way to identify educational mismatches (Verhaest and Omey, 2006). The experts would need to express these required skill levels in the same scale metric as the possessed skills are measured in to directly compare the two.

Finally, we would like to point out an important policy implication of our 'effective skill model'. This model implies that employers may boost productivity by either improving the skill proficiency levels of their workers or increasing the use of the workers' skills. The latter can be achieved more easily than the former by workplace development policies and changes in the job design (Pouliakas and Russo, 2015; Hentschel, 2017; Russo, 2017).

\section{Supplementary material}

Supplementary material is available online at the OUP website. The PIAAC data can be obtained from the OECD website. The Dutch LFS data that were used for this paper are confidential. These data can be obtained by sending a request to Statistics Netherlands. All replication syntax files are available online at the OUP website including a short explanatory note how to use them. The supplementary material also includes the online appendix.

\section{Acknowledgements}

We thank two anonymous reviewers for their comments and suggestions. We also thank Olivier Marie, Ken Mayhew, Seamus McGuinness, Dieter Verhaest, and participants of the 24th Workshop Transitions in Youth (3-5 September 2015, Brno), the Sixth Workshop on Economics of Education (9-10 September 2015, Barcelona), the 12th IHW/IAB Workshop on Labour 
Market Policies (12-13 October 2015, Halle), the Second International PIAAC Conference (2224 November 2016, Haarlem), the DUHR seminar (26 January 2016, Maastricht), the ROA Human Capital over the Life Cycle conference (19-20 February 2016, Maastricht), and the OCW Kennislunch (3 March 2016, The Hague) for useful comments and suggestions.

\section{Funding}

This work was supported by the Dutch Ministry of Education, Culture and Science.

\section{References}

Allen, J. and Bijlsma, I. (2015) Skill Profiles of Occupations: Robust Multi-Level Estimates Based on PIAAC Data, ROA, Maastricht.

Allen, J., Levels, M., and van der Velden, R. (2013) Skill Mismatch and Skill Use in Developed Countries: Evidence from the PIAAC Study, ROA-RM-2013/17, ROA, Maastricht.

Allen, J. and van der Velden, R. (2001) Educational mismatches versus skill mismatches: effects on wages, job-related training, and on-the-job search, Oxford Economic Papers, 53, 434-52.

Allen, J. and van der Velden, R. (2005) The role of self-assessment in measuring skills, REFLEX Working Paper No. 2, ROA, Maastricht.

Altonji, J. and Pierret, C. (2001) Employer learning and statistical discrimination, Quarterly Journal of Economics, 116, 313-50.

Bandura, A. (1977) Self-efficacy: toward a unifying theory of behavioral change, Psychological Review, 84, 191-215.

Battu, H., Belfield, C., and Sloane, P. (2000) How well can we measure graduate overeducation and its effects?, National Institute Economic Review, 171, 82-93.

Becker, G. (1964) Human Capital: A Theoretical and Empirical Analysis, with Special Reference to Education, NBER, New York.

Bijlsma, I., van den Brakel, J., van der Velden, R., and Allen, J. (2017) Estimating Literacy Levels at a Detailed Regional Level: An Application Using Dutch Data, ROA-RM-2017/6, ROA, Maastricht.

Bills, D. (2003) Credentials, signals and screens: explaining the relationship between schooling and job assignment, Review of Educational Research, 73, 441-70.

Bynner, J. and Parsons, S. (1998) Use It or Lose It? The Impact of Time Out of Work on Literacy and Numeracy Skills, Basic Skills Agency, London.

Cedefop (2010) The skill matching challenge: analysing skill mismatch and policy implications, Reference Report No. 3056, Office for Publications of the European Union, Luxembourg.

Cedefop (2015) Skills, qualifications and jobs: The making of a perfect match?, Reference Report No. 3072, Office for Publications of the European Union, Luxembourg.

Collins, R. (1979) The Credential Society: An Historical Sociology of Education and Stratification, Academic Press, New York.

Desjardins, R. (2014) Rewards to skill supply, skill demand, and skill match-mismatch: studies using the Adult Literacy and Lifeskills Survey, Dissertation, Department of Economics, Lund University, Lund.

Desjardins, R. and Warnke, A. (2012) Ageing and skills: a review and analysis of skill gain and skill loss over the lifespan and over time, OECD Education Working Papers No. 72, OECD Publishing, Paris.

Duncan, G. and Hoffman, S. (1981) The incidence and wage effects of overeducation, Economics of Education Review, 1, 75-86.

Freeman, R. (1976) The Overeducated American, Academic Press, New York. 
Green, F., Felstead, A., and Gallie, D. (2013) Skills and work organisation in Britain, in F. Green and M. Keese (eds) Job Tasks, Work Skills and the Labour Market, OECD Publishing, Paris.

Green, F. and McIntosh, S. (2007) Is there a genuine under-utilization of skills amongst the overqualified?, Applied Economics, 39, 427-39.

Groot, W. and Maassen van den Brink, H. (2000) Overeducation in the labor market: a meta-analysis, Economics of Education Review, 19, 149-58.

Guthrie, J. and Wigfield, A. (2000) Engagement and motivation in reading, in M. Kamil, P. Mosenthal, P. Pearson, and R. Barr (eds) Handbook of Reading Research, 3rd edn, Longman, New York, 403-22.

Halaby, C. (1994) Overeducation and skill mismatch, Sociology of Education, 67, 47-59.

Handel, M. (2017) Measuring job content: skills, technology, and management practices, in J. Buchanan, D. Finegold, K. Mayhew, and C. Warhurst (eds) Oxford Handbook of Skills and Training, Oxford University Press, Oxford, 72-123.

Hanushek, E., Schwerdt, G., Wiederhold, S., and Woessmann, L. (2015) Returns to skills around the world: evidence from PIAAC, European Economic Review, 73, 103-30.

Hanushek, E. and Woessmann, L. (2011) The economics of international differences in educational achievement, in E. Hanushek, S. Machin, and L. Woessmann (eds) Handbook of the Economics of Education, vol. 3, Amsterdam, North-Holland, 89-200.

Hartog, J. (2000) Overeducation and earnings: where are we, where should we go?, Economics of Education Review, 19, 131-47.

Heckman, J. and Scheinkman, J. (1987) The importance of bundling in a Gorman-Lancaster model of earnings, Review of Economic Studies, 54, 243-55.

Hentschel, J. (2017) Skills or jobs: which comes first?, IZA World of Labor, 339, 1-9.

Krahn, H. and Lowe, G. (1998) Literacy Utilization in Canadian Workplaces, Statistics Canada and Human Resource Development Canada, Ottawa and Hull.

Levels, M. and van der Velden, R. (2018) Use-it-or-lose-it? Explaining age-related differences in key information processing skills, in I. Kirsch, E. Gonzalez, M. von Davier, and K. Yamamoto (eds) The Importance of Skills and How to Assess Them, Springer International Publishing AG, Cham.

Levels, M., van der Velden, R., and Allen, J. (2014) Educational mismatches and skills: new empirical tests of old hypotheses, Oxford Economic Papers, 66, 959-82.

Marsden, D. (1999) A Theory of Employment Systems: Micro Foundations for Societal Diversity, Oxford University Press, Oxford.

McGuinness, S. (2006) Overeducation in the labor market, Journal of Economic Surveys, 20, 387-418.

McGuinness, S. and Pouliakas, K. (2017) Deconstructing theories of overeducation in Europe: a wage decomposition approach, in S. Polachek, K. Pouliakas, G. Russo, and K. Tatsiramos (eds), Skill Mismatch in Labor Markets, Research in Labor Economics, vol. 45, Emerald Publishing Ltd, Bingley, 81-127.

Mincer, J. (1974) Schooling, Experience, and Earnings, NBER Press, New York.

Mincer, J. and Ofek, H. (1982) Interrupted work careers: depreciation and restoration of human capital, Journal of Human Resources, 17, 3-24.

OECD (2012) Literacy, Numeracy and Problem Solving in Technology-Rich Environments: Framework for the OECD Survey of Adult Skills, OECD Publishing, Paris.

OECD (2013a) Skills Outlook: First Results from the OECD Survey of Adult Skills, vol. 1, OECD Publishing, Paris.

OECD (2013b) Technical Report of the OECD Survey of Adult Skills (PIAAC), OECD Publishing, Paris.

Pellizari, M. and Fichen, A. (2013) A new measure of skills mismatch: theory and evidence from the Survey of Adult Skills (PIAAC), OECD Social, Employment and Migration Working Papers No. 153, OECD Publishing, Paris. 
Pellizari, M. and Fichen, A. (2017) A new measure of skill mismatch: theory and evidence from PIAAC, IZA Journal of Labor Economics, 6, 1.

Perry, A., Wiederhold, S., and Ackermann-Piek, D. (2014) How can skill mismatch be measured? New approaches with PIAAC, Methods, Data, Analyses, 8, 137-74.

Pouliakas, K. and Russo, G. (2015) Heterogeneity of skill needs and job complexity: evidence from the OECD PIAAC Survey, IZA Discussion Paper No. 9392, IZA, Bonn.

Quintini, G. (2011) Over-qualified or under-skilled: a review of existing literature, OECD Social, Employment and Migration Working Papers No. 121, OECD Publishing, Paris.

Russo, G. (2017) Job design and skill development in the workplace, in S. Polachek, K. Pouliakas, G. Russo, and K. Tatsiramos (eds) Skill Mismatch in Labor Markets, Research in Labor Economics, vol. 45, Bingley, Emerald Publishing Ltd, 409-45.

Salthouse, T. (2006) Mental exercise and mental ageing: evaluating the validity of the 'use it or lose it' hypothesis, Perspectives on Psychological Science: A Journal of the Association for Psychological Science, 1, 68-87.

Sattinger, M. (1993) Assignment models of the distribution of earnings, Journal of Economic Literature, 31, 851-80.

Sattinger, M. (2012) Qualitative mismatches, foundations and trends, Microeconomics, 8, 1-168. Spence, M. (1973) Job market signaling, Quarterly Journal of Economics, 87, 355-74.

Thurow, L. (1975) Generating Inequality, Macmillan, London.

Van der Velden, R. and van Smoorenburg, M. (1997) The measurement of overeducation and undereducation: self-report vs. job-analyst method, ROA Research Memorandum 1997/2E, ROA, Maastricht.

Van Iddekinge, C., Aguinis, H., and Mackey, J. (2014) A meta-analysis of the relative and interactive effects of ability and motivation on performance, paper presented at the meeting of the Academy of Management, Philadelphia, PA.

Verhaest, D. and Omey, E. (2006) Measuring the incidence of over- and undereducation, Quality \&uantity, 40, 783-803.

Vroom, V.H. (1964), Work and Motivation, Wiley, New York. 